\title{
The relationship between perception of social interaction, perceived social support and social acceptance with aggression among adolescents
}

Hamid Reza Samadifard ${ }^{1}$, Esmaeil Sadri Damirchi ${ }^{2}$

\author{
Journal of Research \& Health \\ Social Development \& Health Promotion \\ Research Center \\ Vol. 8, No. 1, Jan \& Feb 2018 \\ Pages: $38-46$ \\ DOI: 10.29252/acadpub.jrh.8.1.38 \\ Original Article
}

1. Correspondence to: Department of Psychology, School of Educational Sciences and Psychology, University of Mohaghegh Ardabili, Ardabil, Iran

Email: Hrsamadifard@ymail.com

2. Department of Educational Sciences, School of Educational Sciences and Psychology, University of Mohaghegh Ardabili, Ardabil, Iran

Received: 14 Agu 2016

Accepted: 21 Nov 2016

How to cite this article: Samadifard HR, Sadri Damirchi E. The relationship between perception of social interaction, perceived social support and social acceptance with aggression among adolescents. $J$ Research \& Health2018; 8(1): 38-46.

\begin{abstract}
This study was aimed to investigate the relationship between social interaction, perceived social support and social acceptance with aggression among adolescents. The execution method was a descriptive and correlative. The statistical population of this study included all of the boy adolescent high school students, that sample including 260 participants of boy adolescents were chosen from various locations of the city by adopting a cluster sampling technique. Results indicated that among the perception of social interaction elements; there is positive and significant relationship between negative thoughts and aggression, and negative and significant relationship between positive thoughts and aggression. Also, there is negative and significant relationship between the elements of perceived social support (social support of friends, family and others) and regression. Moreover, there is negative and significant relationship between social acceptance and adolescents' aggression. Thus, it can be concluded that perception of social interaction, perceived social support and social acceptance are significant factors which effect the occurrence or absence of adolescents' aggression.
\end{abstract}

Keywords: Adolescent, Aggression, Interpersonal Relations, Social Distance, Social Support

\section{Introduction}

Aggression is one of the most common problems of adolescents and it is considered as an important reason of their referral to psychotherapists [1]. Aggression, is an intentional behavior harassing someone else which can be conducted directly or indirectly. Aggressive adolescents are not capable to control their own behavior and they violate the traditions and etiquettes of the society [2]. Furthermore, an aggressive adolescent possible commit a crime, they show high levels of antisocial behaviors and they are more tended to narcissism [3]. Aggression disorder in low ages can lead to more damaging impacts in occupational, educational and social areas in higher ages [4]. Another research result has shown that boy adolescents' aggression level is higher than girl adolescents. Adolescence is the indicator of the end of childhood period and the inception of maturity foundation in the three biological, psychological and social aspects [5]. Aggression is the application of an annoying stimulus from one person to another by aiming to annoy or damage 
the receiver. Aggression can have different appearances such as direct or indirect forms [6]. Results of various studies have indicated that there is relationship between social skills and aggression, and instruction of social skills cause the reduction of aggression among adolescents [7]. Researches' results have indicated that family and society support play significant role in aggression non-emergence among adolescents. Also, the research results of Bashiri and Fakhraee showed that adolescents' aggression relies on the factors of family type, social and economic base, occupational status and siblings' educational level [8].

Perception of social interaction is One of the psychological and social factors which can affect the adolescents' aggression. Since humans live a social life, so having an accurate perception of the behavior of others plays an important role in human lives. Perception includes awareness of events, people, objects and situations and it requires searching, acquiring and processing of information. Perception of social interaction is a proactive process which results in understanding of the behaviors of others, also it has different positive and negative forms [9]. Researches results have indicated that perception of social interaction plays role in emergence of adolescents' high risk behaviors. A research's result showed that if adolescent's perception of social interaction is positive, so he/she would have more rational and suitable relationships with his/her peer. Another study has shown that an individual's behavior is under the impression of their perception of physical, social and life conditions. If the high adolescents' perception of conditions is positive, so they would show more rational behaviors in daily matters [10]. Other results have shown that there is significant relationship between adolescents' perception of social interaction and their tendency toward substance abuse [11]. A Study's results have indicated that there is significant relationship between adolescents' perception of social interaction and their social behaviors [12]. Furthermore, the research results of Babakhani \& Memipour in Iran showed that there is significant relationship between emotional intelligence and critical thinking with the perception of social interaction [9]. Results of Yazdkhasti's research indicated that there is a negative and significant relationship between the perception of social interaction and anger and risk taking among university students [10].

Perceived social support can be named one of psychological and social factors affecting adolescents' aggression. This factor significantly effects the physical, psychological and life satisfaction states and different quality aspects of individuals' lives, and it is known as an effective moderating factor in opposition and adaptation to stressful situations of life. Perceived support means the personal perception of support availability, sufficient measure of support and its quality at the required time [13]. Perceived social support as a support network refers to a large and small domain system of individuals who are available at the time for help. Social support is conceptualized in the form of received and perceived support. Perceived social support includes conducted actions of the social network members to help the individual in need [14]. Various researches have shown that favorable perceived social support can reduce the loneliness feeling of adolescents and cause life satisfaction for individuals. Responding to stress is reduced in individuals by increasing social support and it improves individual's' psychological health [15]. Studies has shown that social support is considered as an important factor for positive and remunerative experiences which finally leads to adolescents' self-worth and self-esteem level. A research result indicated that there is significant relationship between perceived social support and adolescents' adaptability [16]. Masoudnia concluded that there is negative and significant relationship between the perceived social support and depression [17]. Results of cheraghi et al showed that there is significant relationship between the perceived social support quality of life [18].

Social acceptance is another factor of this research, which refers to individuals' responses 
according to cultural norms that results in their acceptance and social utility [19]. Problems in social interaction and solving the social issues can result in new problems in social acceptance. Most of the conducted researches in Iran aimed to investigate the social acceptance role in drug addiction. Researches' results have has shown that there is significant diversity between the social acceptances of Internet addicted university students and normal university students [20]. Another research's results showed that there is significant relationship between adolescents' social acceptance and their educational progress. Moreover, there is significant relationship between adolescents' social acceptance and their bullying behavior. Adolescents with low social acceptance level would have higher level of bullying behavior. Another research's results indicated that their social skills will be promoted in adolescents and their social skills will be promoted and they will be less likely to show bullying behavior. Moreover, another study in Iran has shown that comparing to media, social acceptance plays much more significant role in adolescent's orientation to plastic surgery. This study shows the important role of social acceptance in modern societies [21]. Another research has indicated that instruction of social skills causes the increase of social acceptance and decrease of aggression among adolescents [22].

Results of studies indicated that the aggressive adolescent act roughly and aggressively that individual lacks healthy social support or affairs. Therefore, various researches should be conducted concerning this matter, so that the future adolescents' behaviors wouldn't face any crudity [23]. As it was mentioned earlier, various studies have proven the social factors effectiveness in emergence of various adolescents' high risk behaviors. Aggressive behavior is one such behaviors which its exposure in adolescence has harmful effects on elder ages. Such adolescents who do not observe the society's ethics and customs will face serious problems such as anti-social behaviors and committing crimes as they begin their ages of youth or university's period [8]. Considering that perception of social interaction, perceived social support and social acceptance play important roles in adolescents' psychological health and aggression [10,16] and since the level of boy adolescents' aggression is higher than girls [24], investigation of these variables relationships with adolescents' aggression, particularly in boy adolescents seems necessary. Considering the significance of this topic and the mentioned facts, this study was aimed to investigate the relationship between perception of social interaction, perceived social support and social acceptance with aggression among adolescents

\section{Method}

This study is a correlative research. The research data were analyzed by using the Pearson's correlation coefficient. The statistical population of this study includes all boy Ardabil's district 1 adolescents, studying in the level of pre-university level in 20152016, academic years that by the report of Ardabil's district 1 Education administration were consisted of 932 participants. The studied statistical sample volume were determined through adapting Krejcie and Morgan table, and 272 participants were selected as sample from the population volume $(\mathrm{N}=932)$ [25]. The multiphase cluster sampling were used for selecting the study sample. The procedure was that first, four schools were selected randomly out of Ardabil's district 1 schools, and two classes were randomly selected out of each school and they were entered into the study. After setting aside the incomplete returned questionnaires from 272 distributed questionnaires, finally data that were the result of 260 participants' questionnaires were statistically analyzed. The following questionnaires were used:

Perception of social interaction questionnaire: This tool is self-report questionnaire which was developed in order to measure the two factors of negative and positive thoughts toward social interaction. This questionnaire includes 30 questions based on a five degree scale; 1- I have never thought of it; 2- I have 
rarely thought about it; 3- I have sometimes thought about it; 4- I have usually thought about it; 5- I have always thought about it. The reliability of this questionnaire in Iran, it was measured 0.73 in the research of Hadian [26]. In this study, the reliability was calculated 0.81 by using the Cronbach's Alpha technique.

Multidimensional questionnaire for perceived social support: This questionnaire was developed by Zimet et al in order to measure the perceived social support of family, friends and particular individuals of one's life. This scale is of 12 items and the respondent identifies answer in a scale of 5 grade options, which grade 1 represents total disagreement and grade 5 represents total agreement. The internal reliability of this tool were calculated for a 788-individual sample of high school adolescents by using a Cronbach's Alpha test as 0.86 to 0.90 for subscales of this tool and 0.86 were reported for the total tool [27]. Also, the three dimensions of social support perceived from family, friends and important people of one's life were calculated as $0.89,0.86$ and 0.82 respectively by using the Cronbach's Alpha correlation [28]. Similarly, in this study, the reliability of the total score were calculated as 0.80 by using the Cronbach's Alpha technique and also the reliability of the social support perceived from family, friends and important people of one's life were calculated as 0.81 , 0.84 and 0.83 , respectively.

Social acceptance scale: This scale was developed by Crown and Marlo and it includes 33 questions that can be answered in a True or False manner. The purpose of this questionnaire is to assess the level of social acceptance of individuals. High scores in the results of this questionnaire indicate high social acceptance level. Its reliability were calculated higher than 0.80 by using retest. Also, in terms of validity, this test highly corresponded to other psychological tools designed by for measuring the social acceptance of participants [29]. Moreover, in Iran, in the research of Samari and Lalee Faz, the reliability of this questionnaire were measured as 0.74 [30]. In this study, reliability were measured by the Cronbach's Alpha technique for all adolescents as 0.77.

Adolescents' aggression scale: This scale was developed by Orpinas and Frankowski in order to measure the adolescents' aggression level. This scale, considers aggression as a singledimensional structure. This scale is of 11 items and the respondent identifies his answer in a 7 -option scale. Reliability of this scale for boys were measured as 0.88 , for girls as 0.87 , and in general it was measured as 0.87 . Furthermore, researchers in different countries has adapted this scale in order to calculate the adolescents' aggression. Reliability of this scale for Spanish adolescents were measured as 0.86 , for African adolescent students as 0.85 , and for Caucasian students as 0.92 [31]. Also, in Iran, in the research of Akbari et al the reliability of this questionnaire were calculated by Cronbach's Alpha test as 0.82 [22]. In this study, reliability were tested by Cronbach's Alpha technique and the results were 0.80 .

\section{Results}

The Table 1 shows the information related to mean and standard deviation of perception of social interaction, perceived social support, social acceptance and aggression among boy adolescents.

Table 1 Mean and standard deviation of research variables

\begin{tabular}{llcc}
\hline Variable & & M & SD \\
\hline \multirow{2}{*}{ Perception of social interaction } & Negative thoughts & 44.71 & 14.07 \\
& Positive thoughts & 40.74 & 12.08 \\
\hline \multirow{2}{*}{ Perceived social support } & Friends' social support & 11.32 & 2.38 \\
& Family's social support & 11.66 & 2.49 \\
& Others' social support & 11.05 & 2.21 \\
\hline \multirow{2}{*}{ Social acceptance } & & 12.36 & 2.83 \\
Aggression & & 37.67 & 9.77 \\
\hline
\end{tabular}


Table 2 The correlation coefficients (Pearson) of perception of social interaction, perceived social support, social acceptance and aggression among adolescents.

\begin{tabular}{|c|c|c|c|}
\hline Variable & & Statistic & Aggression \\
\hline \multirow{7}{*}{ Perception of social intera } & \multirow{3}{*}{ Negative thoughts } & Pearson coefficient & 0.402 \\
\hline & & & \\
\hline & & Level of significance & 0.001 \\
\hline & \multirow{4}{*}{ Positive thoughts } & & \\
\hline & & Pearson coefficient & -0.621 \\
\hline & & & \\
\hline & & Level of significance & 0.001 \\
\hline \multirow{9}{*}{ Perceived social support } & \multirow{3}{*}{ Friends' social support } & Pearson coefficient & -0.587 \\
\hline & & & \\
\hline & & Level of significance & 0.001 \\
\hline & \multirow{3}{*}{ Family's social support } & Pearson coefficient & -0.559 \\
\hline & & & \\
\hline & & Level of significance & 0.001 \\
\hline & \multirow{3}{*}{ Others' social support } & Pearson coefficient & -0.606 \\
\hline & & & \\
\hline & & Level of significance & 0.001 \\
\hline \multirow{2}{*}{ Social acceptance } & & Pearson coefficient & -0.489 \\
\hline & & Level of significance & 0.001 \\
\hline
\end{tabular}

Table 3 The summery of the standard multiple regression analysis of perception of social interaction, perceived social support and social acceptance in predicting adolescents' aggression

\begin{tabular}{|c|c|c|c|c|c|c|c|c|c|}
\hline & Variable & $\mathrm{B}$ & STE & $\beta$ & $\mathrm{T}$ & Sig & $\mathrm{R}$ & $\mathrm{R}^{2}$ & Adjusted R \\
\hline \multirow{2}{*}{$\begin{array}{l}\text { Perception of } \\
\text { social } \\
\text { interaction }\end{array}$} & Negative thoughts & 0.20 & 0.06 & 0.15 & 3.21 & 0.002 & \multirow{6}{*}{0.72} & \multirow{6}{*}{0.64} & \multirow{6}{*}{0.63} \\
\hline & Positive thoughts & -2.35 & 0.52 & -0.30 & -4.49 & 0.001 & & & \\
\hline \multirow{3}{*}{$\begin{array}{l}\text { Perceived } \\
\text { social } \\
\text { support }\end{array}$} & Friends' social support & -0.54 & 0.43 & -0.10 & -1.24 & 0.112 & & & \\
\hline & Family's social support & -0.67 & 0.30 & -0.13 & -2.20 & 0.029 & & & \\
\hline & Others' social support & -0.80 & 0.29 & -0.17 & -2.79 & 0.006 & & & \\
\hline \multicolumn{2}{|c|}{ Social acceptance } & -0.72 & 0.32 & -0.15 & -2.24 & 0.027 & & & \\
\hline
\end{tabular}

Dependent variables: Aggression

According to the results of the Table 2, among the perception of social interaction variables, there is a positive and significant relationship between negative thoughts and aggression, and a negative and significant relationship between positive thoughts and aggression. Also, the perceived social support variables (social support of family, friends, and others) have a positive and significant relationship with aggression. Moreover, there is a negative and significant relationship between social acceptance and adolescents' aggression $(\mathrm{p}<0.05)$.
In the final step, multiple regression test was used for predicating adolescents' aggressiveness based on their perception of social interaction, perceived social support and social acceptance levels.

The Table 3 results showed that by using the multiple regression method, 0.64 of adolescents' regression was explained by predictor factors (perception of social interaction, perceived social support and social acceptance). Furthermore, the obtained $\mathrm{F}$ is significant. This shows that at least one of the 
predictor variables is significant in predicting adolescent's aggression. Considering the Beta coefficients of table above, it becomes clear that among the predictor variables: perception of social interaction (positive thoughts: -0.30 ; negative thoughts: 0.15 ), perceived social support (family: -0.13 and others: -0.17 ) and the other variable, i.e. social acceptance for -0.15 significant explain adolescents' aggression $(\mathrm{p}<0.05)$.

\section{Discussion}

This study was aimed to investigate the relationship between social interaction, perceived social support and social acceptance with aggression among adolescents. The general results of the study indicated that there is relationship between the perceived social interaction, perceived social support and social acceptance variables with adolescents' aggression. which relationship was as significant positive relationship between perceived social interaction, perceived social support and social acceptance with adolescents' aggression. Since one of this study's goals was to describe the regression model according to predictor variables for predicting adolescents' aggression, so results showed that perceived social interaction, perceived social support and social acceptance have the capability of predicting adolescents' aggression.

The first section indicated that from there is a positive and significant relationship between negative thoughts and aggression and a negative and significant relationship between positive thoughts and aggression among the perceived social interaction components. However, for explaining the obtained results based on Buchanan's opinion, it was realized that adolescents' behaviors in different situations are affected by their perceptions. Adolescents who have a positive perception of situations have favorable behaviors, while adolescents who have a negative perception of situations would show high risk behaviors. Aligned with other researches [10,11], the results of this study indicated that perception of social interaction play an important role in emergence of high risk behaviors in adolescents, including aggression. Johnson and Tversk believed that the positive perception of social interaction result in risky and highly optimistic assessments, and the negative perception of social interaction result in risky and highly pessimistic assessments [12]. Considering the results of this research, adolescents that have positive thoughts about social interaction had lower levels of aggression while adolescents that had negative thoughts about social interaction had higher levels of aggression. This means that positive thoughts cause the reduction of aggression and negative thoughts of social interactions cause the elevation of aggression among adolescents. Song's research showed that the adolescents with high negative perception of social interaction would become more, willingness toward high risk behaviors [11]. Yazdkhasti in research concluded that there is a negative and significant relationship between perception of social interaction with anger and risk taking level among university students. This means that the high one's perception of social interactions is associated, with the lower one's level of anger and risk taking and love one's perception of social interaction is related to higher one's level of anger and risk taking becomes [10]. Moreover, Babakhani and Memipour found that there is a positive and significant relationship between emotional intelligence and perception of social interaction. This means that high level of one's emotional intelligence, is associated with high one's perception of social interaction [9]. Finally, it can be concluded that high one's perception of social interaction is related to, the lower the level of aggression and high one's perception of social interaction is related to, the higher the level of aggression.

Another variable of this study were the perceived social support factor. Aligned with Walcott research, the results of this study showed that social supportis one of the effective factors in the emergence of adolescents' aggression. Results indicated that there is 
negative and significant relationship between the components of perceived social support and aggression. Considering the research results, high level of perceived social support (of family, friends and others) in adolescents, is related to the lower the level of aggression and aggression would be intensified by lowering of these factors among adolescents. The social support theory discusses the various sources that positively or negatively affect the social networks and affairs of individuals. Lundberg believed that adolescents need social support to prove them and they often receive this support from their family or friends. If perceived social support level is high in adolescents, they will have a self-worth feeling within themselves, while if the level of social support is low in them, they are more likely to emerge risky behaviors [32]. As Warren's opinion, perceive social support refers to the individuals mental evaluation of others' supports [16]. Adolescents who sense high levels of social support by their acquaintances will have a higher psychological health [15]. Aggressive adolescents show more inappropriate and aggressive responses towards social matters compared to their unaggressive peers, and they adapt more aggressive solutions for achieving positive consequences [33]. Moreover, aggressive adolescents do not have the necessary skills for presenting efficient responses for matters and they lack the skills of conflict solving [34]. According to the results of this study, adolescents who have high perceived social support are less likely to be aggressive and they will present more appropriate responses to matters. Various researches have proven that by increasing of social support, health level is promoted as well and vice versa. In this perspective, being healthy relies on being socially supported. Tamanaeefar et al found that there is a significant relationship between perceived social interaction and selfefficacy among adolescents. This means that if adolescents are socially supported, so level of self-efficacy would be enhanced is among them and if they were less socially supported, so the level of self-efficacy would be decreased among them [14]. Furthermore, Beyrami et al concluded that there is a relationship between perceived social support and social isolation with students' addiction to the internet [35]. According to their research results, university students with the higher the social support factors are will be less probable to become addicted to the internet and vice versa. Researches' results have shown that as one's level of perceived social support elevates, one is more exposed to depression. Finally, it can be concluded that as the perceived social support in individuals, particularly adolescents elevates, they will be more physically and emotionally healthy and would probably be less exposed to aggression.

Another variable of this study is social acceptance. Results showed that there is a negative and significant relationship between social acceptance and adolescents' aggression. For explaining the obtained result, it can be said considering the acceptance of an individual the sense of belonging to a social group and support is created within the individual by the society, parents and friends. In addition, the individual can then find more friends that increase the quality of own social affairs in its own way. Moreover, the individual can sympathize with others which all of these will lead the individual to use alternative options such as aggression and other risky behaviors while facing life challenges and tensions [35]. The high social acceptance level among adolescents, is associated with less exposed to aggression and the less the level of social acceptance is associated with more exposed to aggression. Social acceptance addresses responses that people give in order to be accepted according to cultural norms. As it was mentioned earlier, most researches have been conducted in Iran focused on studying the role of social acceptance in drug addiction. Results of Gottlieb's research indicated that there is a significant distinction between boys and girls social acceptance [36]. On the other hand, the result of another research results showed that boys are more aggressive than girls [24]. This study results as well showed that there is a significant relationship between 
boy adolescents' social acceptance and their aggression. This study and other mentioned studies' results prove the significance of social acceptance in adolescents' aggression. The results of all the other researches and this research verifies the importance of social acceptance in tendency toward unfavorable behaviors such as aggression.

\section{Conclusion}

The last part of results indicated that 0.64 of adolescents' aggression is explained by perceived social interaction, perceived social support and social acceptance. Finally, considering the results of this research, it can be concluded that the perception of social interaction, perceived social support and social acceptance are three important factors in nonemergence of adolescents' aggression. Thus, the findings of this research can be implemented in prevention of adolescents' aggression.

Some limitations of this study, included statistical population limitation to the adolescent pre-university students of Ardebil and consequently the impossibility of result generalization is of the constraints of this study. Only sample of boy adolescents is one of the other constraints of this study which limits the result generalization to girl adolescents.

It is suggested that future studies can be conducted in other cities, countries, on girl adolescents and also on adolescents of other educational levels, so that results can be more prone to generalization. On the other hand, this is a correlative study and it is not feasible to interpret the data. It is suggested to conduct experimental studies in order to investigate the variables causality. Furthermore, it is suggested to help the adolescents suffering from aggression in the education department and schools counseling centers to reduce their level of aggression by instructing them the social skills and promoting social acceptance and support.

\section{Acknowledgements}

We appreciate the help of all the adolescents and teachers who contributed to this study.

\section{Contribution}

Study design: HRS.

Data collection and analysis: ESD, HRS.

Manuscript preparation: HRS.

\section{Conflict of Interest}

"The authors declare that they have no competing interests."

\section{Funding}

The author (s) received no financial support for the research, authorship and/or publication of this article.

\section{References}

1- Sukhodolsky DG, Kassinove H, Gorman BS. Cognitive-behavioral therapy for anger in children and adolescents: Ameta-analysis. Aggress Violent Behav2004; 9(3): 247-69.

2- Connolly J, Nocentini A, Menesini E, Pepler D, Craig W, Williams TS. Adolescent dating aggression in Canada and Italy: A cross-national comparison. Int J Behav Dev2010: 34: 98-105.

3- Onishi A, Kawabata Y, Kurokawa M, Yoshida T. A mediating model of relational aggression, narcissistic orientations, guilt feelings, and perceived classroom norms. School Psychol Int2012; 33: 367 -90.

4- Ercan E, Ercan ES, Atılgan H, Başay BK, Uysal $\mathrm{T}$, Inci SB, Ardıç UK. Predicting aggression in children with ADHD. Child Adolesc Psychiatry Ment Health2014; 8: 5-15.

5- Zameni L, Farrokhi A, Hasemi Z. The comparison of athletic aggressive tendencies in youth basketball players. Journal of Motor behavior and sport psychology2010; 2(1): 289-99.

6- Polman H. Hot-Headed or cold-blooded? Towards a clear distinction between reactive and proactive aggression in youth. Netherlands: Prins Partners Ipskamp; 2008.

7- Naghdi H, Adibrad N, Nouranipour R. The effectiveness of the emotional intelligence training on the aggressiveness among adolescent boys. $J$ Kermanshah Univ Med Sci2010; 14(3): 211-8.

8- Fakhraee S, Bashiri Khatibi B. Social and cultural factors influencing family violence in Tabriz. Journal of Applied Sociology of Isfahan2013; 24(2): 221-33.

9- Baba Khani V, Memipour M. The relationship between emotional intelligence and critical thinking with perception of social interactions in university students. Journal of Behavioral Sciences2012; 4(14): 61-77.

10- Yazdkhasti F. The relation between perception 
of social interaction with risk taking. Developmental Pscychology2010; 7(26): 187-91.

11- Song AV, Morrell HE, Cornell JL, et al. Perceptions of smoking-related risks and benefits as predictors of adolescent smoking initiation. Am J Public Health2009; 99(3): 487-92.

12- Johnson EJ, Tversk A. Affect, generalization, and the perception of risk. J Pers Soc Psychol1983; 45(1): 20-31.

13- Hesam M, Asayesh H, Ghorbani M, Shariati AR, Nasiri H. The relationship of perceived social support, mental health and life satisfaction in martyrs and veterans students of state university in Gorgan. Journal of Research Development in Nursing and Midwifery2011; 8(1): 34-41.

14- Tamannaeifar M, Leis $H$. The relationship between emotional intelligence, self-efficiency, social support and adjustment in student. Modern Psychological Researchers2015; 10(39): 25-52.

15- Tajalli P, Sobhi A, Ganbaripanah A. The relationship between daily hassles and social support on mental health of university students. Procedia Soc Behav Sci2010; 5: 99-103.

16- Warren JI, Stein JA, Grella CE. Role of social support and self-efficacy in treatment outcomes among clients with co-occurring disorders. Drug Alcohol Depend2007; 89(2-3): 267-74.

17- Masoudnia A. Relationship between perceived social support and risk of postpartum depression disorder. Iran Journal of Nursing2011; 24(70): 8-18.

18- Cheraghi MA, Davari Dolatabadi E, Salavati M, Moghimbeigi A. Association between perceived social support and quality of life in patients with heart failure. Iran Journal of Nursing2012; 25(75): 21-31.

19-Sarbescu P, Costea I, Rusu S. Psychometric properties of the marlowe- crown social desirability scale in a romanian sample. Procedia Soc Behav Sci2012; 33: 707-11.

20- Bayrami M, Movahedi Y, Kharazi Notash H, Albert

S. Comparison of social acceptance and public health in the students with and without internet addiction. Community Health Journal2015; 9(2): 20-8.

21- Abbaszadeh M, Mahmud Mowlai Kermani B, Aghdasi F. Sociological study of the intervening variable of social acceptance in the effectiveness of mass media on the tendency of women to cosmetic surgery. Journal of Women and Society2014; 5(19): 47-66.

22- Akbari Balootbangan A, Rahmani F, Eshghabadi S. Validity and reliability of the aggressiveness scale among students of Semnan, Iran. Journal of Research in Behavior Sciences2016; 14(1): 14-22.
23- Vahedi SH, Fathiazar S. The effect of social competence training on decreasing in aggression pre-school boys. Journal of Fundamentals of Mental Health 2007; 8(32): 131-40.

24- Tucker LW, Parks JB. Effect of gender and sport type on intercollegiate athletes' perception of the legitimacy of aggressive behavior in sport. Social Sport J2001; 18: 403-13.

25- Krejcie RV, Morgan DW. Determining sample size for research activities. Educ Psychol Meas1970; 30: 607-10. 26- Hadian M. Investigation of the relationship between social perception and anger management. [Thesis]. Payame Nour University of Isfahan, Iran 2008.

27- Bruwer B, Emsley R, Kidd M, Lochner C, Seedat $\mathrm{S}$. Psychometric properties of the Multidimensional Scale of Perceived Social Support in youth. Compr Psychiatry2008; 49(2): 195-201.

28- Mohammadi E, Seidabadi M, Zeinalabadi R, Tohidi A, Norouzinia R. The relationship between perceived social support and Test Anxiety: The mediating role of Self-efficacy. Journal of Development Strategies in Medical Education2015; 2(2): 23-33.

29- Hatfield A. Family education: Theory and practice. New Dir Ment Health Serv1994; (62): 3-11.

30- Samari AA, Lalee Faz A. Effectiveness of life skills education on family stress and social acceptance. Journal of Fundamentals of Mental Health2004; 8(2526): 47-55.

31- Orpinas P, Frankowski R. The aggression scale: a self-report measure of aggressive behavior for young adolescents. J Early Adolesc2001; 21(1): 50-67.

32- Lundberg CA, McIntire DD, Creasman CT. Sources of social support and self-efficacy for adult students. Journal of College Counseling2008; 11: 58-72.

33- Frey KS, Hirschstein MK, Guzzo BA. Preventing aggression by promoting social competence. J Emot Behav Disord2000; 8(2): 102-12.

34- Olweus D. Bullies on the playground, the role of victimization. In Hart $\mathrm{CH}$, eds. Children on playgrounds. Albany: State University of New York Press; 1993. pp: 85-128.

35- Beyrami M, Movahedi Y, Movahedi M. The relationship between perceived social support and the feeling of social-emotional loneliness with internet addiction in university students. Social Cognition 2015 ; 3(2): 109-22.

36-Gottlieb BW, Gottlieb J, Berkell D, Levy L. Sociometrist status and solitary, play of LD boys and girls. J Learn Disabil1986; 19: 619- 22.

\footnotetext{
Copyright $(2016$ ASP Ins. This open-access article is published under the terms of the Creative Commons Attribution-NonCommercial 4.0 International License which permits Share (copy and redistribute the material in any medium or format) and Adapt (remix, transform, and build upon the material) under the Attribution-NonCommercial terms.
} 